\title{
Suplementação energética pré-acasalamento aos 13/15 meses de idade para novilhas de corte: desenvolvimento e desempenho reprodutivo
}

\begin{abstract}
Alcides Pilau ${ }^{1}$, José Fernando Piva Lobato $^{2}$
1 Doutorando da Pós-Graduação em Zootecnia/Faculdade de Agronomia-UFRGS. Bolsista CNPq.

2 Departamemnto de Zootecnia/Faculdade de Agronomia - UFRGS. Bolsista CNPq. Caixa Postal 15100, CEP: 90.001-970, Porto Alegre, RS.

RESUMO - Avaliou-se o efeito da suplementação pré-acasalamento no desempenho reprodutivo de novilhas de corte aos 13/15 meses de idade. Foram utilizadas 89 novilhas com média de 12 meses de idade e peso corporal (PC) médio inicial de $242 \mathrm{~kg}$, provenientes de três rebanhos (novilhas Aberdeen Angus das Fazendas Santa Cecília e Capitão Rodrigo e novilhas mestiças Aberdeen Angus) submetidas a regime alimentar exclusivamente em pastejo ou com suplementação a pasto com grão de milho moído. As novilhas foram agrupadas dentro dos regimes alimentares considerando o peso inicial e o rebanho. O suplemento foi fornecido diariamente na proporção de $0,7 \%$ do peso corporal por 29 dias em pastagem de aveia (Avena strigosa Schreb) e azevém (Lolium multiflorum Lam) e 19 dias em pastagem natural. O pastejo foi contínuo com taxa de lotação variável. As variáveis analisadas foram: peso corporal, condição corporal, ganho de peso médio diário, ganho de condição corporal, porcentagem de novilhas púberes, taxa de prenhez e ordem de concepção. Não houve interação regimes alimentares $\times$ rebanhos. Durante o pré-acasalamento, o maior ganho médio diário das novilhas sob suplementação foi maior $(0,800 \mathrm{~kg})$ que o daquelas sem suplementação $(0,658 \mathrm{~kg})$. No período reprodutivo, as novilhas perderam peso, média de $-0,104 \mathrm{~kg} /$ dia. O peso corporal e a condição corporal não diferiram ao início do período reprodutivo, média de $277 \mathrm{~kg}$ e 3,6 pontos, respectivamente. As novilhas sob suplementação apresentaram maior PNP (por extenso) (78\%) e maior taxa de prenhez (47\%). Houve interação rebanho $\times$ período para peso corporal. A variação no peso vivo foi quadrática entre os três rebanhos. O peso corporal das novilhas mestiças foi sempre superior ao das Aberdeen Angus do rebanho Santa Cecília. As novilhas Aberdeen Angus do rebanho Capitão Rodrigo tiveram maior percentagem de novilhas púberes (80\%) e taxa de prenhez (48\%). A suplementação energética por 48 dias pré-acasalamento proporciona maior taxa de prenhez em novilhas de corte aos $13 / 15$ meses de idade.
\end{abstract}

Palavras-chave: condição corporal, desempenho, pastagem cultivada, pastagem nativa, prenhez

\section{Pre-mating energetic supplementation at 13/15 months of age for beef heifers: Development and reproductive performance}

ABSTRACT - The effect was assessed of pre-mating supplementary feeding on the reproductive performance of 13-15 month old beef heifers. Eighty-nine heifers were used with a mean age of 12 months and mean body weight (BW) of $242 \mathrm{~kg}$ from three herds Aberdeen Angus heifers from the Santa Cecilia and Capitao Rodrigo ranches and crossbred Aberdeen Angus heifers) in a feeding system of only grazing pasture or supplemented heifers on pasture with milled corn grain. The supplement was offered daily at the proportion of $0.7 \%$ of the BW for 29 days on Oats (Avena strigosa Schreb) and annual Ryegrass (Lolium multiflorum Lam) cultivated pastures and 19 days on natural pasture. The grazing was continuous with variable stocking rate. The variables analyzed were: body weight, body condition, average daily live weight gain, body condition gain, percentage of pubescent heifers, pregnancy rate and conception order. There was no feeding systems $\times$ herd interaction. During the pre-mating, the supplemented heifers had greater ADG, $0.800 \mathrm{~kg}$, compared to those without supplementation, $0.658 \mathrm{~kg}$. During the mating period, the heifers lost weight, mean of $-0.104 \mathrm{~kg} / \mathrm{day}$. The variables body weight and body condition did not differ at the beginning of the mating period mean of $277 \mathrm{~kg}$ and 3.6 points, respectively. The supplemented heifers showed higher percentage of pubescent heifers (78\%) and higher pregnancy rate $(47 \%)$. There was herd $\times$ period interaction for body weight. The body weight variation was quadratic for the three herds. Crossbred heifers always had greater body weight compared to the Santa Cecília Angus heifers. Capitão Rodrigo Angus heifers had higher higher percentage of pubescent heifers (80\%) and PR (48\%). Energy supplementation during 48 days pre-mating promoted higher pregnancy rate in 13 to 15 month old beef heifers.

Key Words: body condition, cultivated pasture, native pasture, performance, pregnancy 


\section{Introdução}

Uma das características econômicas mais importantes na produção de bovinos de corte é o desempenho reprodutivo das fêmeas. A proporção de animais nascidos e desmamados em relação ao número de fêmeas do rebanho determina grande parte da rentabilidade da atividade (Pötter et al., 2000; Beretta et al., 2001).

A redução da idade ao primeiro serviço traz vantagens, como a diminuição de categorias improdutivas e aumento na quantidade e velocidade de giro do capital no empreendimento. Nos Estados Unidos, onde cerca de 90\% das novilhas são expostas a reprodução aos 13/15 meses de idade (Merck Sharp Dome, 1992), aproximadamente 50\% da energia despendida para a produção de carne é gasta na mantença de vacas na cria (Gregory, 1984; Ferrel \& Jenkins, 1985).

No Brasil, os climas tropical e subtropical possibilitam maior crescimento das forrageiras e de sistemas pecuários sobre estas, com pequena ou nenhuma utilização de grãos ou subprodutos na dieta dos animais. Com base em regimes a pasto, o acasalamento das novilhas aos 13/15 meses de idade vem sendo experimentado por poucos produtores rurais e estudado por pesquisadores na Região sul (Rocha \& Lobato, 2002a; b; Beretta et al., 2001) e na região central do País (Silva et al., 2005).

Alternativas de alimentação devem ser testadas para enriquecer a qualidade da dieta-base, predominantemente pastagens naturais na Região Sul e pastagens tropicais no Cerrado. A introdução de espécies hibernais nos campos naturais sulinos e o uso de suplementação nas pastagens tropicais no período da seca podem contribuir para maiores taxas de ganho de peso na recria e, consequentemente, melhor resposta reprodutiva a idades mais jovens (Pereira Neto \& Lobato, 1998; Vieira et al., 2006). O uso de suplementos energéticos pré-acasalamento pode aumentar o aporte de nutrientes pelos animais, modificando a composição do ganho de peso e proporcionando acúmulo de gordura precocemente (Pilau et al., 2005).

Neste trabalho, considerou-se a hipótese de que, quando utilizado um nível alimentar elevado no pósdesmame, a suplementação energética no período que antecede o início do acasalamento pode ser determinante para o sucesso reprodutivo das novilhas aos 13/15 meses de idade.

Avaliaram-se o desenvolvimento e desempenho reprodutivo de novilhas de corte provenientes de diferentes criatórios, sob suplementação ou não 48 dias préacasalamento e expostas a reprodução com 13 a 15 meses de idade.

\section{Material e Métodos}

O experimento foi realizado em área da Agropecuária Nossa Senhora de Lourdes, município de Tupanciretã, Rio Grande do Sul, primavera-verão de 2003/2004. A propriedade está localizada na região fisiográfica denominada Planalto Médio, com altitude média de $180 \mathrm{~m}$, latitude $29^{\circ} 03^{\prime}$ Sul e longitude $53^{\circ} 48^{\prime}$ Oeste.

O relevo da região é ondulado, com coxilhas de solos profundos, naturalmente ácidos e de textura superficial média. Este solo é classificado como Latossolo Vermelho Distroférrico típico (EMBRAPA, 1999) e o clima da região é subtropical, conforme classificação de Köppen (Moreno, 1961).

Utilizaram-se 89 novilhas contemporâneas com peso médio de $242 \mathrm{~kg}$, provenientes de dois criatórios da região e recriadas em mesma pastagem de aveia-preta (Avena strigosa Schreb) e azevém (Lolium multiflorum Lam) dos 7 aos 11 meses de idade.

Durante o período de pré-acasalamento, 29 dias em pastagem de aveia e azevém em final de ciclo e 19 dias em pastagem natural, as novilhas foram distribuídas em dois regimes alimentares conforme o peso vivo e três rebanhos: 32 novilhas Aberdeen Angus da Fazenda Santa Cecília (Santiago, RS); 25 novilhas Aberdeen Angus da Fazenda Capitão Rodrigo (Jari, RS); 32 novilhas mestiças Aberdeen Angus, também pertencentes à Fazenda Capitão Rodrigo.

Os regimes alimentares foram: exclusivamente em pastejo; e suplementação em pastagens com grão de milho moído durante 48 dias pré-acasalamento. O suplemento foi oferecido diariamente, às $14 \mathrm{~h}$, na proporção de $0,7 \%$ do peso vivo (PV). O método de pastejo foi o contínuo com lotação variável utilizando-se a técnica de animais reguladores (Mott \& Lucas, 1952) para ajuste da capacidade de suporte às massas de forragem pretendidas. Na pastagem de aveia e azevém, procurou-se manter a massa de forragem entre $1.200 \mathrm{e} 1.800 \mathrm{~kg} / \mathrm{ha}$ MS e, na pastagem natural, entre 1.500 e $2.000 \mathrm{~kg} / \mathrm{ha}$ MS. Nos sistemas alimentares sem suplementação e com suplementação, foram alocados 44 e 45 animais-teste, respectivamente, e um número variável de reguladores conforme a necessidade de ajuste da capacidade de suporte.

O ajuste de capacidade de suporte e as medidas de massa de forragem, taxa de acúmulo de forragem e oferta de forragem foram realizadas em intervalos de aproximadamente 28 dias. A massa de forragem foi determinada pela técnica de dupla amostragem (Wilm et al., 1944). Para determinação da taxa de acúmulo diário, foram alocadas cinco gaiolas de exclusão ao pastejo por pasto, utilizando-se metodologia 
descrita por Klingmann et al. (1943). A oferta de forragem foi calculada dividindo-se a massa de forragem por 28 dias somada à taxa de acúmulo diário. $\mathrm{O}$ valor obtido foi multiplicado por 100 e dividido pela capacidade de suporte.

A determinação do valor nutritivo da forragem foi realizada em amostras de forragem colhidas por meio de simulação de pastejo (Gibb \& Treacher, 1976). Os parâmetros avaliados foram: na forragem, proteína bruta (PB) e fibra detergente neutro (FDN) e, no suplemento, PB e nutrientes digestíveis totais (NDT). As técnicas utilizadas foram as descritas pela AOAC (1984).

Durante a suplementação na pastagem cultivada, a área total de 37 ha foi dividida em dois pastos. Posteriormente, na pastagem natural, os animais foram manejados em duas áreas de 45 ha. Em ambas as pastagens, os grupos de animais trocavam de pasto a cada sete dias visando eliminar o efeito de área sobre o desempenho individual. Não houve separação dos grupos raciais quanto ao manejo alimentar.

O período reprodutivo foi em pastagem natural, numa área de 90 ha comum para todos os regimes alimentares. Foram utilizados cinco touros Red Angus de 3 anos de idade, submetidos a exame andrológico prévio. O controle de endoparasitos foi realizado por meio de dosificações dos animais no início do período de pastejo e posteriormente a cada três pesagens. O ganho de peso médio diário (GMD) foi obtido pela diferença entre peso final e inicial dos animais-teste em cada período experimental dividido pelo número de dias do período.

As novilhas foram pesadas individualmente após jejum de 12 horas. No pré-acasalamento, as pesagens foram realizadas no início (28/9/2003) e ao final da suplementação na pastagem cultivada e, ao início da suplementação, na pastagem natural (27/10/2003). No período reprodutivo, as pesagens foram feitas ao início $(15 / 11 / 2003)$, no período intermediário (24/12/2003) e no final (30/1/2004). Em cada pesagem, foi avaliado o escore de condição corporal (Lowman et al., 1973), com valores de 1 a 5, em que 1 = muito magro e 5 = muito gordo.

Ao início da estação de acasalamento, foi realizada avaliação do trato reprodutivo por meio de exame de ultrassonografia com um transdutor transretal linear de 5 $\mathrm{MHz}$ de frequência. A metodologia utilizada foi adaptada de Andersen (1991), com escores de 1 a 5, em que $1=$ trato reprodutivo imaturo e 5 atividade cíclica normal, com presença de corpo lúteo. O diâmetro do maior folículo e/ou a presença de corpo lúteo foram tomados como parâmetros de avaliação. Para posterior análise, os dados foram classificados em porcentagem de novilhas púberes (PNP), considerando púberes aquelas com ETR 4 ou 5 e nãopúberes aquelas de ETR 1; 2 ou 3.
O diagnóstico de gestação foi realizado 28 dias após o término do período de acasalamento (27/2/2003) pela técnica de ultrassonografia com um transdutor transretal linear de $5 \mathrm{MHz}$ de frequência. As novilhas foram classificadas pelo desenvolvimento do embrião ou feto quanto ao período da concepção em novilhas prenhes no terço inicial, intermediário ou final da estação de monta, respectivamente.

O delineamento experimental foi o inteiramente casualizado em arranjo fatorial $3 \times 2$, com parcelas subdivididas no tempo. Os dados coletados foram submetidos à análise de variância e ao teste $\mathrm{F}$, utilizando-se o modelo estatístico:

$\mathrm{Y}_{\mathrm{ijkl}}=\mu+\mathrm{R}_{\mathrm{i}}+\mathrm{S}_{\mathrm{j}}+(\mathrm{R} * \mathrm{~S})_{\mathrm{ij}}+\mathrm{A}_{\mathrm{k}}(\mathrm{R} * \mathrm{~S})_{\mathrm{ij}}+\mathrm{P}_{1}+(\mathrm{R} * \mathrm{P})_{\mathrm{il}}+$ $(\mathrm{S} * \mathrm{P})_{\mathrm{j} 1}+(\mathrm{R} * \mathrm{~S} * \mathrm{P})_{\mathrm{ijl}}+\varepsilon_{\mathrm{ijk} 1}$;

em que: $Y_{i j k l}=$ variáveis dependentes; $\mu=$ média geral; $R_{i}=$ efeito do i-ésimo rebanho; $S_{j}=$ efeito do j-ésimo nível de suplementação; $R_{i}{ }^{*} S_{j}=$ efeito de interação entre o i-ésimo rebanho e o j-ésimo nível de suplementação; $A_{k}(R * S)_{i j}=$ efeito do k-ésimo animal dentro da interação entre o i-ésimo rebanho e o j-ésimo nível de suplementação; (erro A); $\mathrm{P}_{1}=$ efeito do l-ésimo período; $\mathrm{R} * \mathrm{P}_{\mathrm{il}}=$ efeito de interação entre o i-ésimo rebanho e o l-ésimo período; $\mathrm{S} * \mathrm{P}_{\mathrm{j} 1}=$ efeito de interação entre o j-ésimo nível de suplementação e o l-ésimo período; $\mathrm{R} * \mathrm{~S} * \mathrm{P}_{\mathrm{ijl}}=$ efeito de interação entre o i-ésimo rebanho, o j-ésimo nível de suplementação e o l-ésimo período; $\varepsilon_{\mathrm{ijkl}}=$ erro residual (erro B).

Quando detectada diferença entre os rebanhos, o nível de suplementação, o período ou a interação entre os mesmos, foi realizado o teste Tukey para comparação de médias. Em caso de interação com período, foi realizada análise de regressão polinomial até segunda ordem. As análises foram feitas utilizando-se o procedimento general linear model (GLM). Os dados referentes à porcentagem de novilhas púberes, à taxa de prenhez e período da concepção foram analisados pelo método do Qui-quadrado. O programa estatístico utilizado foi o SAS versão 6.08 (SAS, 1997). Foi adotado 5\% como o nível de significância máximo das análises.

\section{Resultados e Discussão}

O ajuste da capacidade de suporte na pastagem natural provocou redução de 2.490 para $1.887 \mathrm{~kg} / \mathrm{ha}$ MS na massa de forragem e de 26,1 para $18,8 \mathrm{~kg} \mathrm{MS} / 100 \mathrm{~kg}$ de peso corporal na oferta de forragem do período pré-acasalamento até o final do período reprodutivo (Tabela 1). A amplitude de oferta de forragem recomendada por Maraschin et al. (1997) para a melhor resposta produtiva dos animais em pastagem natural é de 11,5 a 13,5 kg de MS/100 kg de peso corporal. A carga animal utilizada não permitiu a redução 
da oferta de forragem inicial para os valores preconizados do ponto de vista do manejo da pastagem natural.

A quantidade de forragem disponível aos animais foi passível de pastejo seletivo. Entretanto, a qualidade da forragem aparentemente consumida foi um dos fatores limitantes ao desempenho dos animais, principalmente em decorrência do alto teor de FDN. Conforme Mertens (1987), o potencial de consumo de forragem pelo animal é de 1,2\% do PV em FDN. Altos teores de FDN limitam o consumo de forragem pelos animais, porém é dependente ainda do tipo da dieta e das interações com outros efeitos de regulação (Van Soest, 1994).

Não houve efeito da interação rebanho × suplementação alimentar nas variáveis estudadas, portanto, os efeitos de cada fator foram apresentados separadamente. A suplementação no período de pré-acasalamento proporcionou maior ganho médio diário durante o pastejo em aveia e azevém e no período inicial da pastagem natural (Tabela 2). As novilhas sob suplementação tiveram ganho médio diário de $0,800 \mathrm{~kg}$, enquanto aquelas mantidas em regime de pasto ganharam $0,658 \mathrm{~kg} /$ animal.dia.

As novilhas vinham sendo alimentadas desde a desmama para apresentarem ganho de peso médio superior a $0,600 \mathrm{~kg} /$ dia durante a recria, visando peso mínimo necessário para a concepção aos 13/15 meses de idade. O maior ganho de peso durante os 48 dias de suplementação pré-acasalamento possivelmente está associado ao maior consumo de matéria seca total pelos (Tabela 1). Se o grão é incluído na dieta do animal, a energia metabolizável da forragem é substituída em parte pela do grão (Dixon \& Stockdale, 1999). Em geral, a redução no consumo de forragem quando grãos são fornecidos é menor que o acréscimo no consumo de grãos, resultando em maior consumo total de matéria seca (Rearte \& Pieroni, 2001).

Durante o período reprodutivo, tanto as novilhas somente a pasto como aquelas sob suplementação préacasalamento tiveram perda de peso, média de $0,104 \mathrm{~kg} /$ animal/dia. A taxa de ganho de peso está relacionada à quantidade de gordura do animal (Di Marco, 1998). Quando o nível de consumo é alto, ocorre maior retenção de proteína e gordura, assim como aumento substancial de vísceras e órgãos, consequentemente, aumenta o custo de mantença. Este efeito é maior em animais jovens, que têm maior peso relativo desses componentes (Rompala \& Hoagland, 1987). Quando ocorre diminuição no consumo, o peso desses tecidos diminui, reduzindo o custo de mantença ( $\mathrm{Di}$ Marco, 1998).

A perda de peso das novilhas no período reprodutivo pode estar relacionada à diminuição no tamanho dos órgãos internos, provocada pela diminuição no consumo de forragem. Em trabalho com a mesma categoria animal, Rocha et al. (2004) comprovaram perda de peso das novilhas

Tabela 1 - Massa de forragem, taxa de acúmulo diário de forragem, oferta de forragem e carga animal na pastagem de aveia e azevém na primavera e na pastagem natural no verão

\begin{tabular}{|c|c|c|c|c|}
\hline \multirow{3}{*}{$\begin{array}{l}\text { Variável } \\
\text { Pastagem } \\
\text { Período }\end{array}$} & \multicolumn{2}{|c|}{ Suplementação pré-acasalamento } & \multirow{2}{*}{\multicolumn{2}{|c|}{$\begin{array}{c}\text { Acasalamento } \\
\text { Natural** } \\
\end{array}$}} \\
\hline & \multirow{2}{*}{$\begin{array}{c}\text { Cultivada* } \\
28 / 9 \text { a } 27 / 10 / 2003\end{array}$} & Natural** & & \\
\hline & & $28 / 10$ a $15 / 11 / 2003$ & $16 / 11$ a $24 / 12 / 2003$ & $25 / 12 / 2003$ a $30 / 1 / 2004$ \\
\hline Massa de forrage & 1530 & 2490 & 2055 & 1887 \\
\hline Taxa de acúmulo diário ( $\mathrm{kg} / \mathrm{ha} \mathrm{MS})$ & 76,8 & 26,1 & 26,1 & 15,3 \\
\hline Oferta de forragem $(\mathrm{kg} \mathrm{MS} / 100 \mathrm{~kg} \mathrm{PV})$ & 15,1 & 26,1 & 22,6 & 18,8 \\
\hline Carga animal $(\mathrm{kg} / \mathrm{ha} \mathrm{PV})$ & 869 & 441 & 439 & 437 \\
\hline
\end{tabular}

* Proteína bruta média $(\mathrm{PB})=13,5 \%$; fibra detergente neutra média $(\mathrm{FDN})=69,1 \%$.

$* * \mathrm{~PB}=9,9 \%, \mathrm{FDN}=71,1 \%$.

Suplemento - grão de milho moído $(0,7 \% \mathrm{PV}), \mathrm{PB}=8,1 \%$, NDT $=80,1 \%$.

Tabela 2 - Ganho de peso diário (kg/animal) e ganho de condição corporal (pontos, 1 a 5) de novilhas de corte com ou sem suplementação energética pré-acasalamento e durante o acasalamento em pastagem natural aos 13/15 meses de idade

\begin{tabular}{|c|c|c|c|c|c|c|}
\hline \multirow[t]{4}{*}{ Regime alimentar } & \multicolumn{6}{|c|}{ Período } \\
\hline & \multirow{2}{*}{\multicolumn{2}{|c|}{$\begin{array}{l}\text { Pré-acasalamento } \\
29 / 9 \text { a } 15 / 11 / 2003\end{array}$}} & \multirow{2}{*}{\multicolumn{2}{|c|}{$\begin{array}{l}\text { Acasalamento } \\
16 / 11 / 2003 \text { a } 30 / 1 / 2004\end{array}$}} & \multirow{2}{*}{\multicolumn{2}{|c|}{$\begin{array}{c}\text { Total } \\
29 / 9 / 2003 \text { a } 30 / 1 / 2004\end{array}$}} \\
\hline & & & & & & \\
\hline & $\begin{array}{c}\text { Ganho médio } \\
\text { diário }\end{array}$ & $\begin{array}{l}\text { Ganho de } \\
\text { condição corporal }\end{array}$ & $\begin{array}{l}\text { Ganho médio } \\
\text { diário }\end{array}$ & $\begin{array}{l}\text { Ganho de } \\
\text { condição corporal }\end{array}$ & $\begin{array}{l}\text { Ganho médio } \\
\text { diário }\end{array}$ & $\begin{array}{l}\text { Ganho de } \\
\text { condição corporal }\end{array}$ \\
\hline Pastejo exclusivo & $0,658 \mathrm{~B}$ & 0,35 & $-0,091$ & $-0,25$ & 0,196 & 0,10 \\
\hline Pasto + suplemento & $0,800 \mathrm{~A}$ & 0,42 & $-0,117$ & $-0,33$ & 0,235 & 0,09 \\
\hline Média & & 0,39 & $-0,104$ & $-0,29$ & 0,216 & 0,10 \\
\hline CV $(\%)$ & 10,11 & 13,50 & 49,71 & 24,28 & 13,76 & 13,50 \\
\hline
\end{tabular}

Médias A, B na mesma coluna, diferem entre si $(\mathrm{P}<0,05)$.

Suplemento: grão de milho moído, $0,7 \%$ peso corporal. 
de $0,185 \mathrm{~kg} /$ animal.dia quando estas saíram da pastagem cultivada de inverno com suplementação e foram para pastagem natural sem suplementação.

A suplementação em pastagens é uma prática que envolve custos adicionais significativos ao sistema de produção e deve ser usada de forma estratégica. Os incrementos em ganho de peso devem estar relacionados ao planejamento forrageiro para a categoria animal envolvida, o qual muitas vezes envolve períodos com pastagens de alta qualidade e outras de qualidade limitante.

O ganho de condição corporal (média de 0,4 ponto) não foi influenciado pela suplementação pré-acasalamento. No período de acasalamento, a perda de peso dos animais foi acompanhada de perda de condição corporal de 0,3 ponto. Considerando todo o período de avaliação, as novilhas apresentaram ganho médio diário de $0,206 \mathrm{~kg}$ e ganho de condição corporal de 0,1 ponto e praticamente mantiveram a condição corporal inicial. Quando o ganho de peso é alto, o animal acumula mais gordura que proteína, independentemente de sua idade ou peso. Por outro lado, quando o ganho de peso é limitado, a retenção de gordura é mais afetada, situação mais evidente em animais jovens e leves, pois relativamente acumulam pouca gordura (Di Marco, 1998).

A suplementação não alterou o peso e a condição corporal das novilhas ao início do período reprodutivo (Tabela 3). O peso corporal médio foi de $277 \mathrm{~kg}$ e a média de condição corporal de 3,6 pontos. O peso a ser atingido no início da estação de acasalamento, conforme o NRC (1996), para Bos taurus, é cerca de $60 \%$ do peso na maturidade em raças produtoras de carne. Animais Bos indicus atingem a puberdade em idade mais elevada e com maior peso relativo, em torno de $65 \%$ do seu peso na maturidade. Segundo Wiltbank et al. (1985), as novilhas devem atingir 65 a 70\% do seu peso adulto na maturidade sexual e devem estar em condição corporal moderada no início de sua primeira estação de acasalamento.

O peso adulto médio das fêmeas dos rebanhos deste experimento foi de $460 \mathrm{~kg}$ e representa a média do peso das vacas destinadas ao abate com aproximadamente $28 \%$ de gordura na carcaça, considerado pelo NRC (1996) como o peso à maturidade. Dessa forma, ao início do acasalamento, as novilhas tinha na média $60 \%$ do peso adulto, com variação de $\pm 22,6 \mathrm{~kg}$, coeficiente de variação $(\mathrm{CV})$ de $8,16 \%$, e condição corporal média de 3,6. Um grande número de novilhas tinham peso corporal limitado para a concepção.

Entre as novilhas sob suplementação, observou-se taxa de $78 \%$ de novilhas púberes no início do período reprodutivo, superior à de $50 \%$ entre aquelas em pastejo exclusivo, sem suplementação. A maior ingestão de energia aumenta a pulsatilidade da secreção de hormônio luteinizante, o que está associado ao aparecimento mais precoce da puberdade (Schillo, 1992). A maior ingestão de alimento nos animais é ocasionada pelo efeito aditivo do suplemento sobre o consumo total de MS, que aumenta a concentração de ácidos graxos voláteis (AGV) no rúmen. O ácido propiônico é capaz de estimular a secreção de insulina, além de ser o principal precursor de glicose em ruminantes (Van Soest, 1994).

A situação metabólica favorável em animais com maior consumo de energia aumenta os níveis de glicose, insulina e fator de crescimento I - tipo insulina (IGF-I) (Santos \& Amstalden, 1998). Todos esses metabólitos parecem influenciar a atividade secretória hipotalâmica-hipofisária (Schillo, 1992; Butler \& Smith, 1989) e potencializar o efeito das gonadotrofinas nas células ovarianas (Spicer \& Echternkamp, 1995). A porcentagem de novilhas púberes ao início do período reprodutivo pode ser considerada um grande sinalizador da taxa de prenhez (Ferreira, 1999; Pereira Neto et al., 1999).

A composição da dieta com maior aporte energético aos animais sob suplementação foi determinante da taxa de prenhez (Tabela 4). Assim como na taxa de novilhas púberes, a taxa de prenhez foi maior nas novilhas sob suplementação $(47 \%$ em relação àquelas em pastejo exclusivo, $25 \%$ ), o que comprova a correlação positiva entre esses parâmetros. Leaflet (1999) avaliou 1.017 novilhas até estas atingirem $65 \%$ do seu peso à maturidade e verificou correlação positiva entre ETR e taxa de prenhez. O número de novilhas prenhes aumentou conforme ETR elevou.

As novilhas dos regimes alimentares não diferiram quanto ao período da concepção. Entretanto, $31 \%$ das prenhes conceberam no terço inicial e $62 \%$ no terço intermediário do período reprodutivo. A habilidade da novilha em conceber cedo na estação de acasalamento está relacionada ao seu manejo nutricional pós-desmame, resultado de uma harmonia entre genótipo e ambiente (Lesmeister et al., 1973; Reynolds et al., 1991).

Tabela 3 - Peso vivo médio, condição corporal média e taxa de novilhas púberes (PNP) ao início do período de acasalamento

\begin{tabular}{lccc}
\hline Regime alimentar & $\begin{array}{c}\text { Peso } \\
\text { vivo (kg) }\end{array}$ & $\begin{array}{c}\text { Condição } \\
\text { corporal (1 a 5) }\end{array}$ & $\begin{array}{c}\text { Novilhas } \\
\text { púberes(\%) }\end{array}$ \\
\hline Pastejo exclusivo & 274 & 3,6 & $50 \mathrm{~b}$ \\
Pasto + suplemento & 279 & 3,6 & $78 \mathrm{a}$ \\
Média & 277 & 3,6 & \\
CV (\%) & 8,17 & 6,73 & \\
\hline
\end{tabular}

Médias a, b na mesma coluna diferem entre si $(\mathrm{P}<0,01)$.

Suplemento: grão de milho moído, $0,7 \% \mathrm{PV}$. 
Tabela 4 - Taxa de prenhez e período da concepção de novilhas de corte submetidas ou não a suplementação alimentar por 48 dias préacasalamento aos $13 / 15$ meses de idade

\begin{tabular}{|c|c|c|c|c|}
\hline \multirow[t]{2}{*}{ Regime alimentar } & \multirow[t]{2}{*}{ Taxa de prenhez (\%) } & \multicolumn{3}{|c|}{ Período da concepção (\%) } \\
\hline & & Inicial & Intermediário & Final \\
\hline Pastejo exclusivo & $25 \mathrm{~B}$ & 18 & 72 & 10 \\
\hline Média & & 31 & 62 & 7 \\
\hline
\end{tabular}

Médias A, B na mesma coluna, diferem entre si $(\mathrm{P}<0,05)$;

Suplemento: grão de milho moído, $0,7 \% \mathrm{PV}$.

Não houve interação entre rebanho e suplementação (Figura 1). A interação foi significativa entre rebanho e período, com um valor de mínima significância de 19,9 kg.

Os pesos dos três rebanhos tiveram resposta quadrática no decorrer do período experimental. Foram verificadas elevadas taxas de ganho de peso no período correspondente à pastagem de aveia e azevém no pré-acasalamento (28/9 a 27/10). Conforme a equação, o aumento foi de $1,115 \mathrm{~kg}$ a cada dia a mais de pastejo para as novilhas Angus da Santa Cecília, enquanto as Angus da Capitão Rodrigo e as mestiças Angus tiveram aumento estimado de 0,856 e $0,883 \mathrm{~kg} / \mathrm{dia}$ neste período. No período de acasalamento, ocorreu desaceleração na taxa de ganho de peso, que se torna negativa no período final para os três rebanhos.

A curva de crescimento animal apresenta uma forma sigmóide, onde o período de inflexão é representado pela puberdade. Em situações não-limitantes, essa inflexão ocorre por volta dos 12 meses de idade com a desaceleração do crescimento e a ovulação (Owens et al., 1993). Portanto, a menor taxa de ganho pré-acasalamento estimada para as novilhas Angus da Capitão Rodrigo e as mestiças Angus em relação às Angus da Santa Cecília pode estar associada à inflexão da curva de crescimento e, consequentemente, à puberdade.
O valor de mínima significância de 19,9 kg mostra um menor peso médio das Angus da Santa Cecília em relação às demais novilhas, exceto ao início do período reprodutivo quando estas novilhas tiveram peso semelhante ao das Angus da Capitão Rodrigo. Apesar das taxas de variação distintas no PC conforme o período, as novilhas mestiças Angus foram sempre mais pesadas que as Angus da Santa Cecília.

Os coeficientes de determinação $\left(\mathrm{R}^{2}\right)$ das equações para os rebanhos Angus da Capitão Rodrigo de 0,168 e as mestiças Angus de 0,164 demonstram que o período influencia apenas cerca de $16 \%$ da variação do PC entre esses animais no pré e durante o acasalamento. Já a variação do PC nas novilhas Angus da Santa Cecília foi influenciada em 41,6\%, conforme o $R^{2}$ de 0,416. Esta situação demonstra que as Angus da Santa Cecília estão em uma fase distinta da curva de crescimento em relação às Angus da Capitão Rodrigo e às mestiças Angus.

As novilhas mestiças Angus chegaram ao início do período da reprodução com condição corporal de 3,7, valor superior à de 3,5 verificada nas Angus da Santa Cecília e Angus da Capitão Rodrigo (Tabela 5). Mesmo sendo inferior, a condição corporal destas novilhas não foi determinante para o desempenho reprodutivo. Em trabalho com novilhas

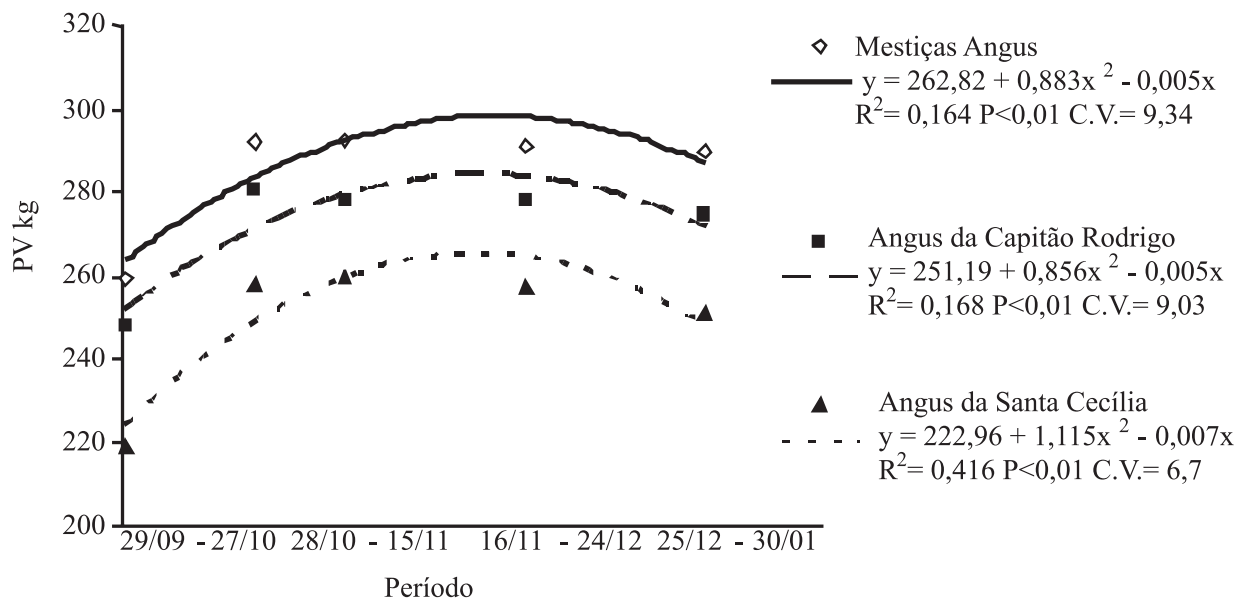

Figura 1 - Evolução do peso vivo de novilhas de três rebanhos durante 48 dias pré e 77 dias de acasalamento aos 13/15 meses de idade. 
acasaladas aos 13/15 meses de idade com taxa de prenhez de 58\%, Rocha \& Lobato (2002b) observaram condição corporal média de 3,6 pontos ao início do período reprodutivo nas novilhas que viriam a ficar prenhes.

A percentagem de novilhas púberes das Angus da Capitão Rodrigo foi de $80 \%$ sendo superior a das mestiças Angus de 69\% e das Angus da Santa Cecília de 47\%, as quais também diferiram entre si. Quanto a taxa de prenhez, o rebanho Angus da Capitão Rodrigo apresentou 48\% de prenhez, taxa superior apenas à do rebanho Angus da Santa Cecília com $22 \%$. O maior número de novilhas com estro ao início do período reprodutivo foi determinante para a maior taxa de prenhez das Angus da Capitão Rodrigo.

Características ligadas a fatores genéticos podem ter influenciado em grande parte a resposta reprodutiva. Em ambientes desfavoráveis, onde a taxa reprodutiva é subótima, a herdabilidade da característica fertilidade em muitos rebanhos é média, suficiente para que significativo progresso genético possa ser feito por seleção e descarte (Deese \& Koger, 1967). Quando as condições do ambiente apresentam restrições para o desenvolvimento normal, novilhas manejadas em condições idênticas podem apresentar desempenhos diferentes associados ao genótipo (Beretta \& Lobato, 1996; Pereira Neto \& Lobato, 1998).

Nos três rebanhos estudados, as taxas de prenhez ficaram abaixo de $50 \%$, demonstrando também a necessidade de seleção para precocidade sexual e consequente viabilidade do acasalamento de novilhas de corte aos 13/15 meses de idade em rebanhos comerciais. Embora a condição alimentar no período pré-acasalamento tenha possibilitado PNP média de $66 \%$, essa condição não foi suficiente para atingir taxa de prenhez média superior a $36 \%$, possivelmente em razão da perda de peso das novilhas dos distintos regimes alimentares no período de acasalamento. Revisão de Ferreira (1993) mostra que, em novilhas mais leves, uma pequena porcentagem de perda de peso pode ocasionar parada da atividade ovariana.

Tabela 5 - Condição corporal e porcentagem de novilhas púberes ao início do período de acasalamento e taxa de prenhez aos $13 / 15$ meses de idade

\begin{tabular}{|c|c|c|c|}
\hline Rebanho & Condição corporal ( 1 a 5 ) & Taxa de novilhas púberes (\%) & Taxa de prenhez $(\%)$ \\
\hline Angus da Santa Cecília & $3,5 b$ & $47 \mathrm{c}$ & $22 \mathrm{~B}$ \\
\hline Angus da Capitão Rodrigo & $3,5 b$ & $80 \mathrm{a}$ & $48 \mathrm{~A}$ \\
\hline Mestiças Angus & $3,7 \mathrm{a}$ & $69 b$ & 39AB \\
\hline CV $(\%)$ & 6,73 & & \\
\hline
\end{tabular}

a, b na mesma coluna, diferem entre si $(\mathrm{P}<0,01)$.

A,B na mesma coluna, diferem entre si $(\mathrm{P}<0,05)$

\section{Conclusões}

A suplementação energética por 48 dias préacasalamento não altera o desenvolvimento corporal de novilhas de corte acasaladas aos13/15 meses de idade. A suplementação energética por 48 dias pré-acasalamento proporciona maior número de novilhas púberes ao início do período da reprodução e maior taxa de prenhez aos 13/15 meses de idade. Novilhas provenientes de diferentes rebanhos respondem de formas diferentes à suplementação energética por 48 dias pré-acasalamento, o que comprova estarem em diferentes fases de crescimento. A maior taxa de prenhez não está condicionada ao rebanho de maior desenvolvimento corporal.

\section{Literatura Citada}

ANDERSEN, K.J. The use of reproductive tract scoring in beef heifers. Agri-Practice, v.12, n.4, p.19-26, 1991.

ASSOCIATION OF OFFICIAL ANALYTICAL CHEMISTS AOAC. Official methods of analysis. 14.ed. Washington, D.C., 1984. $1141 \mathrm{p}$.
BERETTA, V.; LOBATO, J.F.P. Efeitos da ordem de utilização de pastagens melhoradas no ganho de peso e desempenho reprodutivo de bezerras de corte. Revista Brasileira de Zootecnia, v.25, n.1, p.46-57, 1996.

BerettA, V.; LOBATO, J.F.P.; Mielitz NeTto, C.G.A. Produtividade e eficiência biológica de sistemas pecuários diferindo na idade das bezerras ao primeiro parto e na taxa de natalidade do rebanho no Rio Grande do Sul. Revista Brasileira de Zootecnia, v.30, n.4, p.1278-1286, 2001.

BUTLER, W.R; SMITH, R.D. Interrelationships between energy balance and postpartum reproductive function. Journal Dairy Science, v.72, p.767-783, 1989.

DEESE, R.E.; KOGER, M. Herdability of reproduction. In: CUNHA, T.J.; WARNICK, A.C.; KOGER, M. (Ed.). Factors affecting calf crop. Gainesville: University of Florida Press, 1967. p.232-238.

DI MARCO, O.N. Crecimiento de vacunos para carne. 2.ed. Mar Del Prata: República Argentina, 1998. 246p.

DIXON, R.M.; STOCKDALE, C.R. Associative effects between forages and grains: consequences for feed utilization. Australian Journal Agricultural Resarch, v.50, p.757-773, 1999.

EMPRESA BRASILEIRA DE PESQUISA AGROPECUÁRIA EMBRAPA. Centro Nacional de Pesquisa de Solos. Sistema brasileiro de classificação de solos. Brasília: EMBRAPA, 1999. 412p.

FERREIRA, A. Nutrição e atividade ovariana em bovinos: uma revisão. Pesquisa Agropecuária Brasileira, v.28, n.9 p.1077-1093, 1993. 
FERREIRA, M.B.D. Escore do aparelho reprodutivo pré-estação de monta em novilhas zebu aos dois anos de idade. Revista Brasileira de Reprodução Animal, v.23, n.3, p.160-162, 1999.

FERREL, C.L.; JENKINS, T.G. Cow type and the nutricional environment: nutritional aspects. Journal of Animal Science, v.61, n.3, p.725-741, 1985.

GIBB, M.J.; TREACHER, T.T. The effect of herbage allowance on herbage intake and performance of lambs grazing perennial ryegrass and red clover swards. Journal of Agricultural Science, v.86, p.355-365, 1976.

GREGORY, K.E. Beef cattle types. Journal of Animal Science, v.58, n.1, p.234-243, 1984

KLINGLMANN, D.L.; MILES, S.R.; MOTT, G.O. The cage method for determining consumption and yield of pasture herbage. Journal of Society of Agronomy, v.35, p.739-746, 1943.

LEAFLET, A.S. Clinical use of reproductive tract scoring to predict pregnancy outcome. Ames: Iowa State University, 1999. $116 \mathrm{p}$

LESMEISTER, J.L.; BURFENING, P.J.; BLACKWELL, R.L. Date of first calving in beef cows and subsequent calf production. Journal of Animal Science, v.36, n.1, p.1-6, 1973.

LOWMAN, B.G.; SCOTT, N.; SOMERVILle, S. Condition scoring beef cattle. Edinburgh: East of Scotland College of Agriculture, 1973. 8p.

MARASCHIN, G.E.; MOOJEN, E.L.; ESCOTEGUY, C.M.D. et al. Native pasture, forage on offer and animal response In: INTERNATIONAL GRASSLAND CONGRESS, 18., 1997, Saskatoon. Proceedings... Saskatoon: IGA, 1997. v.2. p.288.

MERCK SHARP DOME - MSD. Improved reproductive performance in heifers. New Jersey: Copyright, 1992. 53p.

MERTENS, D.R. Predicting intake and digestibility using mathematical models of al function. Journal of Animal Science, v.64, p.1548, 1987.

MORENO, J.A. Clima do Rio Grande do Sul. Porto Alegre: Secretaria da Agricultura, 1961. 41p.

MOTT, G.O.; LUCAS, H.L. The design conduct and interpretation of grazing trials on cultivated and improved pastures. In: INTERNATIONAL GRASSLAND CONGRESS, 6., 1952, Pensylvania. Proceedings... Pensylvania: State College Press, 1952. p.1380-1395.

NATIONAL RESEARCH COUNCIL - NRC. Nutrient requirement of beef cattle. Washington, D.C.: National Academy Press, 1996. 242p.

OWENS, F.N.; DUBESKI, P.; HANSON, C.F. Factors that alter the growth and development of ruminants. Journal of Animal Science, v.71, n.12, p.3138-3150, 1993.

PEREIRA NETO, O.A.; LOBATO, J.F.P. Efeitos da ordem de utilização de pastagens nativas melhoradas no desenvolvimento e comportamento reprodutivo de novilhas de corte. Revista Brasileira de Zootecnia, v.27, n.1, p.60-65, 1998.

PEREIRA NETO, O.; LOBATO, J.F.P; SIMEONE, A. Sistema de pastejo rotativo ponta e rapador para bezerras de corte. 1. Desempenho corporal. Revista Brasileira de Zootecnia, v.28, n.1, p.137-142, 1999.

PILAU, A.; ROCHA, M.G.; RESTLE, J. et al. Desenvolvimento de bezerras de corte recebendo ou não suplementação energética em pastagem hibernal sob diferentes disponibilidades de forragem. Revista Brasileira de Zootecnia, v.34, n.5, p.1483-1492, 2005

PÖTTER, L.; LOBATO, J.F.P.; MIELITZ NETTO, C.G.A. Análises econômicas de modelos de produção com novilhas de corte primíparas aos dois anos, três e quatro anos de idade. Revista Brasileira de Zootecnia, v.29, n.3, p.861-870, 2000.

REARTE, D.H.; PIERONI, G.A. Supplementation of temperate pastures. In: INTERNATIONAL GRASSLAND CONGRESS, 19. 2001, São Paulo. Proceedings... São Paulo: Sociedade Brasileira de Zootecnia, 2001. p.679-689.

REYNOLDS, W.L.; URICK, J.J.; KNAPP, P.W. et al. Maternal breed of sire effects on post weaning performance of firs-cross heifers and production of two year-old heifers characteristics. Journal of Animal Science, v.69, n.12, p.4368-4376, 1991 .

ROCHA, M.G.; LOBATO, J.F.P. Sistemas de alimentação pósdesmama de bezerras de corte para acasalamento com 14/15 meses de idade. Revista Brasileira de Zootecnia, v.31, n.4, p.1814-1822, 2002a.

ROCHA, M.G.; LOBATO, J.F.P. Avaliação do desempenho reprodutivo de bezerras de corte primíparas aos dois anos de idade. Revista Brasileira de Zootecnia, v.31, n.3, p.1388-1395, 2002b.

ROCHA, M.G.; PILAU, A.; SANTOS, D.T. et al. Desenvolvimento de bezerras de corte submetidas a diferentes sistemas alimentares. Revista Brasileira de Zootecnia, v.33, n.6, p.2123-2131, 2004 (supl.2).

ROMPALA, R.E.; HOAGLAND, T.A. Effect of level of alimentation on visceral organ mass and the morphology and $\mathrm{Na}^{+}, \mathrm{K}^{+}$adenosinetriphosphatase activity of intestinal mucosa in lambs. Journal of Animal Science, v.65, n.7, p.10581063, 1987.

SANTOS, J.E.P.; AMSTALDEN, M. Effects of nutrition on bovine reproduction. IN: REUNIÃO ANUAL SBTE, 13., 1998, Atibaia. Anais... Porto Alegre: UFRGS, 1998. p.19-89.

SCHILLO, K.K. Effects of dietary energy on control of luteinizing hormone secretion in cattle and sheep. Journal of Animal Science, v.70, n.12, p.1271-1282, 1992.

SILVA, J.A.V.; DIAS, L.T.; ALBUQUERQUE, L.G. Estudo genético da precocidade sexual de novilhas em um rebanho Nelore. Revista Brasileira de Zootecnia, v.34, n.5, p.1568-1572, 2005.

SPICER, L.J.; ECHTERNKAMP, S.E. The ovarian insulin and insulinlike growth factor system with an emphasis on domestic animals. Domestic Animal Endocrinology, v.12, p.223-245, 1995.

STATISTICAL ANALYSIS SYSTEM - SAS. SAS/STAT user's guide: statistics. Version 6. 4.ed. Cary: SAS Institute, 1997. v. $2,943 p$

VAN SOEST, P.J. Nutritional ecology of the ruminant. 2.ed Cornel University: Cornel University Press, 1994. 476p.

VIEIRA, A.; LOBATO, J.F.P.; CORREA, E.S. et al. Desenvolvimento e desempenho reprodutivo de novilhas Nelore criadas a pasto nos cerrados do Centro-Oeste brasileiro. Revista Brasileira de Zootecnia, v.35, n.1, p.186-192, 2006.

WILM, H.G.; COSTELLO, D.F.; KLIPPLE, G.E. Estimating forage yield by the double-sampling methods. Journal of American Society of Agronomy. v.36, p.194-203, 1944.

WILTBANK, J.N.; ROBERTS, J.N.; ROWDEN, L. Reproductive performance and profitability of heifers feed to weigh 272 or $318 \mathrm{~kg}$ at the start of the first breeding season. Journal of Animal Science, v.60, n.1, p.25-35, 1985. 